\title{
Effects of theophylline and ipratropium bromide on exercise performance in patients with stable chronic obstructive pulmonary disease
}

\author{
Mitsuhiro Tsukino, Koichi Nishimura, Akihiko Ikeda, Takashi Hajiro, Hiroshi Koyama, \\ Takateru Izumi
}

For patients with stable chronic obstructive pulmonary disease (COPD), recent therapeutic recommendations have suggested that theophylline should be used only as a third choice drug if combined inhaled anticholinergic agents and inhaled $\beta_{2}$ agonists fail to improve a patient's condition. ${ }^{12}$ The goal of treatment in COPD is to improve exercise tolerance and decrease handicap. With respect to the beneficial effects of theophylline on exercise capacity, the results of previous studies have been conflicting. ${ }^{3-9}$ To our knowledge no study has yet demonstrated additional benefits of theophylline on exercise capacity when added to a dose optimised inhaled anticholinergic agent.

The purpose of the present study was to compare the short term effect of an oral theophylline with an inhaled anticholinergic agent and to examine the additional effect of combined therapy on exercise performance using progressive cycle ergometry in patients with stable COPD.

\section{Methods}

Twenty four men with clinically stable COPD as defined by the American Thoracic Society ${ }^{10}$ were recruited between April 1994 and July 1995. Entry criteria included age over 50 years, a history of cigarette smoking of more than 20 pack years, chest radiographs showing hyperinflation, a forced expiratory volume in one second $\left(\mathrm{FEV}_{1}\right)$ of less than $70 \%$ of the predicted value, a best post-bronchodilator $\mathrm{FEV}_{1} /$ forced vital capacity (FVC) of less than 0.7 , and the absence of other disorders likely to affect exercise. Those with an exacerbation of their pulmonary disease within the last three months, a history of asthma, hypoxaemia defined as $\mathrm{a} \mathrm{PaO}_{2}$ of less than $8 \mathrm{kPa}$ at rest, treatment with oral bronchodilators and oral or inhaled corticosteroids in the preceding three months were excluded. Baseline pulmonary function tests were performed within the 14 day period preceding the study. Each subject underwent progressive exercise studies on at least three occasions before entering the trial. Written informed consent was obtained from all patients.

This study was performed in a randomised, double blind, placebo controlled, crossover fashion at approximately the same time on four separate days within a three week period. The interval between testing ranged from four to five days. After baseline studies had been completed, patients entered into the study underwent four separate treatment regimens: (1) 
Table 1 Baseline clinical data of the 21 patients who completed the study

\begin{tabular}{|c|c|c|}
\hline & Mean (SD) & Range \\
\hline Age & $65.4(7.4)$ & $51-77$ \\
\hline Smoking (pack years) & $58.7(28.0)$ & $20-120$ \\
\hline $\mathrm{FEV}_{1}(\mathrm{l})$ & $1.00(0.40)$ & $0.51-2.02$ \\
\hline $\mathrm{FEV}_{1}(\%$ predicted $)$ & $36.1(13.1)$ & $18.5-62.3$ \\
\hline FVC (1) & $2.58(0.61)$ & $1.35-3.78$ \\
\hline FVC (\% predicted $)$ & $73.7(16.2)$ & $38.3-97.6$ \\
\hline $\mathrm{FEV}_{1} / \mathrm{FVC}(\%)$ & $38.7(10.8)$ & $21.2-58.7$ \\
\hline $\operatorname{TLC}(1)$ & $6.14(0.99)$ & $4.15-8.80$ \\
\hline TLC (\% predicted) & $110.2(14.8)$ & $72.7-140.8$ \\
\hline RV/TLC (\%) & $51.0(8.8)$ & $37.5-69.1$ \\
\hline TLCO $(\mathrm{mmol} / \mathrm{min} / \mathrm{kPa})$ & $5.77(1.48)$ & $2.95-8.57$ \\
\hline TLCO $(\%$ predicted $)$ & $71.2(18.7)$ & $33.2-107.9$ \\
\hline $\mathrm{KCO}(\mathrm{mmol} / \mathrm{min} / 1 / \mathrm{kPa})$ & $1.22(0.39)$ & $0.64-2.15$ \\
\hline Resting $\mathrm{PaO}_{2}(\mathrm{kPa})$ & $10.0(1.2)$ & $8.1-12.3$ \\
\hline Resting $\mathrm{PaCO}_{2}(\mathrm{kPa})$ & $5.5(0.5)$ & $4.3-6.7$ \\
\hline
\end{tabular}

$\mathrm{FEV}_{1}=$ forced expiratory volume in one second $; \mathrm{FVC}=$ forced vital capacity $;$ TLC = total lung capacity; $R V=$ residual volume; $\mathrm{T}$ LCO $=$ carbon monoxide transfer factor; KCO = carbon monoxide transfer coefficient; $\mathrm{PaO}_{2}, \mathrm{PaCO}_{2}=$ arterial oxygen and carbon dioxide tensions.

theophylline and ipratropium bromide; (2) theophylline and placebo; (3) placebo and ipratropium bromide; (4) placebo and placebo. The patients were randomly assigned to one of the four treatment regimens according to the 4 $\times 4$ Latin square design.

Sustained-release theophylline (Slow-bid, Rhône-Poulenc Rorer Japan, Tokyo, Japan) or matching placebo were each administered for three days. Patients weighing less than $60 \mathrm{~kg}$ received a dose of $600 \mathrm{mg}$ a day, and those weighing more than $60 \mathrm{~kg}$ received $800 \mathrm{mg}$ a day. During each treatment period the patients took individualised tablets twice daily at 08.00 hours and 20.00 hours. On the third day the patients received $160 \mu \mathrm{g}$ ipratropium bromide (eight puffs of Atrovent, Nippon Boehringer Ingelheim Co Ltd, Kawanishi, Japan) or matching placebo from a metered dose inhaler with a spacer device (InspirEase, ScheringPlough K.K., Osaka, Japan) at 11.00 hours.

The patients were requested to stop taking inhaled bronchodilators for at least 12 hours before starting the exercise test. Pulse rate and blood pressure at rest and spirometric parameters were assessed before and at 90 and 120 minutes after inhalation. After obtaining the spirometric measurement at 90 minutes, symptom limited progressive cycle ergometry was performed as described in our previous

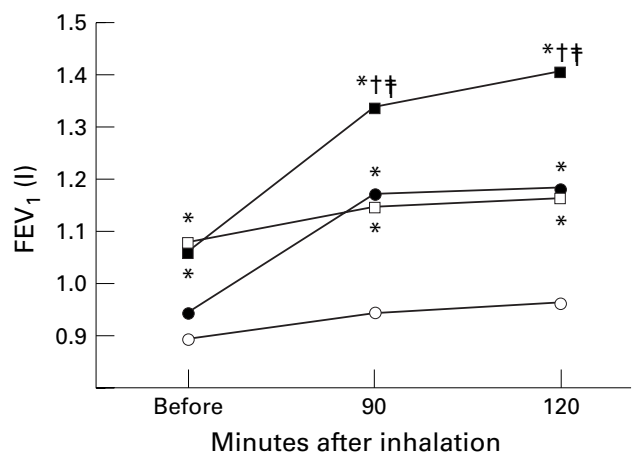

Figure 1 Time-response curve of forced expiratory volume in one second $(F E V)$ after inhalation. $\bigcirc=$ placebo; $\bullet=$ ipratropium bromide; $\square=$ theophylline; $\mathbf{\square}=$ theophylline and ipratropium bromide. ${ }^{\star} p<0.05$ versus placebo; $t p<0.05$ versus ipratropium bromide; $\neq p<0.05$ versus theophylline.

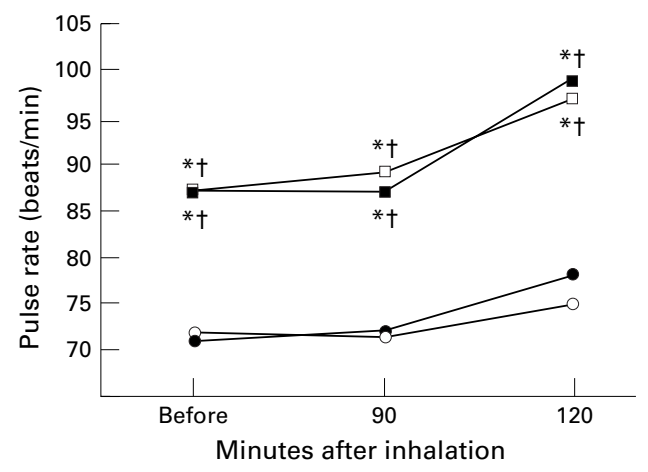

Figure 2 Time-response curve of pulse rate after inhalation. $\circ=$ placebo; $\bullet=$ ipratropium bromide; $\square=$ theophylline; $\mathbf{\mathbf { a }}=$ theophylline and ipratropium bromide. ${ }^{\star} p<0.05$ versus placebo; $t p<0.05$ versus ipratropium bromide.

report. ${ }^{11}$ An electrically braked cycle ergometer (Corival WLP-400, Lode, Groningen, The Netherlands) was used to increase the exercise work load progressively by increments of one watt every three seconds to the limit of tolerance. During exercise symptoms of leg effort and breathlessness were scored using the Borg scale (0 to 10). ${ }^{12}$ Maximum work rate (Wmax) was defined as the highest work level that was reached. Similarly, maximum heart rate (HRmax), oxygen uptake ( $\left.\dot{\mathrm{V}}_{2} \mathrm{max}\right)$, carbon dioxide production $\left(\dot{\mathrm{V}} \mathrm{CO}_{2} \mathrm{max}\right)$, and minute ventilation (VEmax) were the end point levels reached during exercise. The predicted maximum ventilation capacity (V́Ecap) was calculated using the equation $\left(37.5 \times \mathrm{FEV}_{1}\right)$ by Carter et al. ${ }^{13}$ The $\mathrm{FEV}_{1}$ value was used at 90 minutes after inhalation. The predicted heart rate capacity (HRcap) was calculated using the equation $(210-0.65 \times$ age $) .{ }^{14}$ The dyspnoea ratios were expressed as the ratio of the change in the Borg scale value ( $\triangle \mathrm{BS}$ ) to the maximum work rate $(\Delta \mathrm{BS}-\mathrm{Wmax})$, to the change in $\dot{\mathrm{V}}_{2}$ $\left(\Delta \mathrm{BS}-\Delta \dot{\mathrm{VO}}_{2}\right)$ and to the change in $\dot{\mathrm{V}}_{\mathrm{E}}(\Delta \mathrm{BS}-$ $\Delta \dot{\mathrm{V}} \mathrm{E})$. The patients were asked to note any side effects at each time period. Blood samples for the assay of theophylline were collected just before exercise and serum theophylline concentrations were determined by fluorescence polarisation immunoassay using an analyser (TDx, Dainabot, Tokyo, Japan).

The significance of differences among values observed for the four treatment regimens was determined by a repeated measures ANOVA. When a significant difference existed among groups, a contrast analysis was used to identify where differences were significant. A $p$ value of less than 0.05 was considered significant for all tests.

\section{Results}

Of the 24 patients enrolled, 21 completed the study. Three patients dropped out, two patients discontinued theophylline because of its adverse effect (tachycardia and arrhythmia) and one patient had an acute exacerbation during the study. Baseline values for the 21 patients who were evaluated are provided in table 1 . The doses of theophylline/placebo administered daily were $800 \mathrm{mg}$ to 16 patients and $600 \mathrm{mg}$ to five patients. The mean (SD) serum 
Table 2 Exercise data (mean differences from placebo with 95\% confidence intervals)

\begin{tabular}{llll}
\hline & Ipratropium bromide & Theophylline & $\begin{array}{l}\text { Theophylline and } \\
\text { ipratropium bromide }\end{array}$ \\
\hline $\mathrm{Wmax}(\mathrm{Watts})$ & $3.9(-0.8$ to 8.5$)$ & $7.1(3.0 \text { to } 11.2)^{\star}$ & $12.1(6.3 \text { to } 18.0)^{\star}$ \\
$\dot{\mathrm{V}} \mathrm{O}_{2} \mathrm{max}(\mathrm{ml} / \mathrm{min})$ & $40(7 \text { to } 73)^{\star}$ & $77(32 \text { to } 122)^{\star}$ & $123(62 \text { to } 183)^{\star}$ \\
$\dot{\mathrm{V}} \mathrm{CO}_{2} \mathrm{max}(\mathrm{ml} / \mathrm{min})$ & $52(0 \text { to } 104)^{\star}$ & $69(17 \text { to } 121)^{\star}$ & $160(93 \text { to } 228)^{\star}$ \\
$\dot{\mathrm{V}} \mathrm{max}(1 / \mathrm{min})$ & $2.2(0.7 \text { to } 3.8)^{\star}$ & $4.4(2.4 \text { to } 6.4)^{\star}$ & $8.5(6.2 \text { to } 10.9)^{\star}$ \\
$\mathrm{HRmax}^{\star}(\mathrm{beats} / \mathrm{min})$ & $1(-2$ to 5$)$ & $16(10 \text { to } 22)^{\star}$ & $19(15 \text { to } 24)^{\star}$ \\
$\mathrm{SaO}_{2}$ at end of exercise $(\%)$ & $-1(-2$ to 1$)$ & $1(-0$ to 2$)$ & $0(-1$ to 2$)$ \\
Borg score before load & $-0.2(-0.5$ to 0.1$)$ & $-0.1(-0.5$ to 0.2$)$ & $0.1(-0.4$ to 0.5$)$ \\
Borg score at Wmax & $-0.3(-0.5$ to 0.0$)$ & $-0.1(-0.3$ to 0.2$)$ & $0.0(-0.2$ to 0.3$)$ \\
\hline
\end{tabular}

Wmax $=$ maximum work rate $; \dot{\mathrm{V}}_{2} \max =$ maximum oxygen consumption; $\dot{\mathrm{V}}_{\mathrm{CO}_{2}} \max =$ maximum carbon dioxide production; $\dot{V}$ Emax $=$ maximum minute ventilation; $\mathrm{HRmax}=$ maximum heart rate; $\mathrm{SaO}_{2}=$ arterial oxygen saturation

${ }^{\star} \mathrm{p}<0.05$. ipratropium bromide, theophylline, and a combination of both drugs, respectively. A combination of both drugs produced greater improvements in $\mathrm{FEV}_{1}$ than either drug alone $(\mathrm{p}<0.05)$. The mean pulse rate at each time point with theophylline was greater than that without theophylline ( $\mathrm{p}<0.05$; fig 2 ).

The values of $\dot{\mathrm{V}}_{2} \max , \dot{\mathrm{V}} \mathrm{CO}_{2} \max$ and $\dot{\mathrm{V}} \mathrm{Emax}$ increased significantly $(\mathrm{p}<0.05)$ with theophylline or ipratropium bromide when compared with placebo (table 2). Theophylline also showed a greater increase in Wmax than placebo $(p<0.05)$, whereas ipratropium bromide did not. There were no differences between theophylline and ipratropium bromide in Wmax, $\dot{\mathrm{V}}_{2} \max , \dot{\mathrm{V}} \mathrm{CO}_{2} \max$, and $\dot{V}$ Emax. A combination therapy produced greater increases in Wmax, $\mathrm{VCO}_{2} \max$, and VEmax than either drug alone $(\mathrm{p}<0.05)$. The mean (SD) ratio of VंEmax to Vंecap was 1.19 (0.35), 1.00 (0.28), $1.06(0.28)$, and 0.98 (0.25) for placebo, ipratropium bromide, theophylline, and a combination of both drugs, respectively. The mean HRmax with theophylline was significantly greater than without theophylline $(p<0.05)$. The mean $(S D)$ ratio of HRmax to HRcap was $0.71(0.08), 0.72$ (0.08), 0.81 (0.10), and $0.83(0.09)$ for placebo, ipratropium bromide, theophylline, and a combination of both drugs, respectively.

There were no differences between the study group in $\mathrm{SaO}_{2}$ at end of exercise, Borg score before load, and maximal Borg score. The mean (SD) maximal Borg score of placebo, ipratropium bromide, theophylline, and a combination of both drugs were 8.6 (1.6), 8.3 (1.8), 8.5 (1.7) and $8.6(1.6)$, respectively. The three dyspnoea ratios $\left(\Delta \mathrm{BS}-\mathrm{W} \max , \Delta \mathrm{BS}-\Delta \dot{\mathrm{V}}_{2}\right.$, and $\Delta \mathrm{BS}-\Delta \dot{\mathrm{V}} \mathrm{E})$ with theophylline or ipratropium bromide were lower than those with placebo ( $\mathrm{p}<0.05$; fig 3 ). Combination therapy produced lower values for all three dyspnoea ratios than ipratropium bromide alone $(\mathrm{p}<0.05)$ and also produced a lower ratio of $\Delta \mathrm{BS}-\Delta \dot{\mathrm{V}} \mathrm{E}$ than theophylline alone $(\mathrm{p}<0.05)$.

\section{Discussion}

This study used an explanatory analysis rather than an intention to treat, and the maximum clinically permissible dosage of each drug was administered in order to produce the maximum therapeutic action. Since our previous report ${ }^{11}$ showed that the inhalation of ipratropium bromide at doses of $160 \mu \mathrm{g}$ or more was necessary to improve maximal cycle exercise capacity in patients with stable COPD, we administered $160 \mu \mathrm{g}$ of ipratropium bromide in the present study. The effect of theophylline on exercise capacity in patients with COPD has been controversial. The conflicting results of some studies $^{3-9}$ may be attributed to different levels of theophylline and to different methodologies for measuring exercise capacity. The bronchodilating effects of theophylline seemed to be dose dependent in the usual therapeutic range. ${ }^{6} 715$ Moreover, Chrystyn et al showed that exercise performance assessed by six minute walking was dose dependent. McKay et al showed that high doses of theophylline $(17 \mu \mathrm{g} / \mathrm{ml})$ improved exercise performance as assessed by the
Figure 3 Mean (SD) values of three dyspnoea ratios: the ratio of the changes in Borg score ( $\triangle B S$ ) to the maximum work rate ( $\triangle B S-W m a x)$, to the changes in $\dot{V}_{O_{2}}$ $\left(\Delta B S-\Delta \dot{V}_{2}\right)$, and to the changes in $V_{E}\left(\Delta B S-\Delta \dot{V}_{E}\right)$. ${ }^{\star} p<0.05$ versus placebo; $t p<0.05$ versus ipratropium bromide; $¥ p<0.05$ versus theophylline. 
treadmill test, but that low doses $(10 \mu \mathrm{g} / \mathrm{ml})$ did not. These findings suggested that higher doses of theophylline may be needed to achieve beneficial effects on exercise capacity, and our data support this. The use of high dose theophylline in our study resulted in a mean serum theophylline concentration of approximately $18 \mu \mathrm{g} / \mathrm{ml}$, which was in the submaximal therapeutic range and was thought to produce improvements in exercise capacity.

In recommended doses theophylline has less of a bronchodilator effect than anticholinergic agents in patients with COPD. ${ }^{15}$ However, the results of our study show that high dose theophylline had a similar bronchodilating effect to that of ipratropium bromide and produced additional improvements even when four times the clinically recommended dose of ipratropium bromide was used. We speculate that the former effect may be due to the doseresponse effect of theophylline, as discussed above, and the latter effect may be due to differences in the mechanism of action between theophylline and ipratropium bromide.

The ratio of VEmax to VEcap was more than 1.0 and the ratio of HRmax to HRcap was less than 0.83 in every group. These data suggest that ventilatory rather than cardiovascular mechanics were the limiting factor in the exercise test. Furthermore, the present study showed that all scores on the Borg scale were more than 8 at Wmax, which was greater than that shown previously. ${ }^{16}$ This suggests that dyspnoea may be an important limiting factor in addition to ventilatory mechanics. Ikeda $e t a l^{11}$ reported that the correlation between improvements in exercise capacity and improvements in $\mathrm{FEV}_{1}$ when anticholinergic agents were administered was significant. However, this correlation was weak and, in the present study, there was no correlation between the change in Wmax and the change in $\mathrm{FEV}_{1}$. These results support the theory that improvements in exercise capacity are not solely dependent on reductions in airflow limitation.

Several studies ${ }^{717}$ have reported that theophylline reduced the severity of dyspnoea in patients with COPD. Thus, theophylline may prevent the development of the sensation of dyspnoea during exercise and would therefore be expected to improve exercise tolerance. In our study three dyspnoea ratios $(\Delta \mathrm{BS}-\mathrm{Wmax}$, $\Delta \mathrm{BS}-\Delta \dot{\mathrm{VO}}_{2}$, and $\left.\Delta \mathrm{BS}-\Delta \dot{\mathrm{V}} \mathrm{E}\right)$ with theophylline alone were lower than those with placebo. On the other hand, Teramoto et $a l^{18}$ reported that anticholinergic agents possibly improved dyspnoea when they analysed the relationship between the Borg scale and oxygen uptake during exercise. In our study ipratropium bromide slightly but significantly improved the dyspnoea ratios, measured as $\Delta \mathrm{BS}-\mathrm{Wmax}, \Delta \mathrm{BS}-\Delta \dot{\mathrm{V}}_{2}$, and $\Delta \mathrm{BS}-\Delta \dot{\mathrm{V}}_{\mathrm{E}}$, when compared with placebo. Reductions in the sensation of dyspnoea with ipratropium bromide may therefore be partly related to improvements in exercise capacity.

The results of this study represent the short term effects of theophylline administration over a period of three days and/or the effects of a single dose of ipratropium bromide. Although a single high dose of ipratropium bromide had no adverse effects in this study and a previous study, ${ }^{11}$ no evidence has been found of tolerance to high doses of anticholinergic agents during chronic therapy. Adverse effects of theophylline increase considerably at levels more than $15 \mu \mathrm{g} / \mathrm{ml}$ and thus would pose a problem in clinical practice in an elderly patient group. Furthermore, data from cycle ergometer exercise tests are not directly relevant to usual exercise patterns. The results of our study may not therefore be directly applied to long term therapy.

Although high dose theophylline was used in this study, two patients had low serum theophylline concentrations of less than $10 \mu \mathrm{g} /$ $\mathrm{ml}$. They were thought to be protocol violations. There is little difference between analyses including and excluding these subjects, and therefore the former analysis is provided.

In conclusion, high dose theophylline and high dose ipratropium bromide both improved cycle exercise capacity in patients with stable COPD. In addition, high dose combinations of both drugs can produce additional improvements in exercise capacity beyond either drug alone. However, our study evaluated the short term effects of these therapeutic agents and these effects may be different with chronic dosing. Further study is therefore needed to evaluate the effects of long term therapy.

This study was partly supported by a research grant from the Smoking Research Foundation of Japan. The authors thank Ms Kazuyo Haruna and Ms Yumiko Tomita for measuring pulmonary function and Dr Kazuo Kawakatsu for preparing the drugs and for determining the theophylline concentration in serum samples.

1 Siafakas NM, Vermeire P, Pride NB, et al. European Respiratory Society. Optimal assessment and management of chronic obstructive pulmonary disease. Eur Respir $f$ 1995;8:1389-420.

2 Celli BR, Snider GL, Heffner J, et al. American Thoracic Society. Standards for the diagnosis and care of patients
with chronic obstructive pulmonary disease. Am $\mathscr{F}$ Respir With chronic obstructive pulmonary

3 Eaton ML, MacDonald FM, Church TR, et al. Effects of theophylline on breathlessness and exercise tolerance in patients with chronic airflow obstruction. Chest 1982;82: patients

4 Marvin PM, Baker BJ, Dutt AK, et al. Physiologic effects of oral bronchodilators during rest and exercise in chronic obstructive pulmonary disease. Chest 1983;84:684-9.

5 Guyatt GH, Townsend M, Pugsley SO, et al. Bronchodilators in chronic airflow limitation. Am Rev Respir Dis 1987; 135:1069-74.

6 Chrystyn H, Mulley BA, Peake MD. Dose response relation to oral theophylline in severe chronic obstructive airways disease. BMF 1988;297:1506-10.

7 McKay SE, Howie CA, Thomson AH, et al. Value of theophylline treatment in patients handicapped by chronic obstructive lung disease. Thorax 1993;48:227-32.

8 Fink G, Kaye C, Sulkes J, et al. Effects of theophylline on exercise performance in patients with severe chronic obstructive pulmonary disease. Thorax 1994;49:332-4.

9 Mahler DA, Matthay RA, Snyder PE, et al. Sustained-release theophylline reduces dyspnea in nonreversible obstructive theophylline reduces dyspnea in nonreversible obst

10 Medical Section of the American Lung Association. Standards for the diagnosis and care of patients with chronic obstructive pulmonary disease (COPD) and asthma. $\mathrm{Am}$ Rev Respir Med 1987;136:225-44.

11 Ikeda A, Nishimura K, Koyama $\mathrm{H}$, et al. Dose response study of ipratropium bromide aerosol on maximum exercise performance in stable patients with chronic obstructive pulmonary disease. Thorax 1996;51:48-53.

12 Borg GAV. Psychophysical bases of perceived exertion. Med Sci Sports Exerc 1982;14:377-81.

13 Carter R, Peavler M, Zinkgraf S, et al. Predicting maximal exercise ventilation in patients with chronic obstructive pulmonary disease. Chest 1987;92:253-9.

14 Jones NL, Campbell EJM. Clinical exercise testing. 2nd ed. Philadelphia: WB Saunders, 1982: 119.

15 Vozeh S, Kewitz G, Perruchoud A, et al. Theophylline serum concentration and therapeutic effect in severe acute bronchial obstruction: the optimal use of intravenously administered aminophylline. Am Rev Respir Dis 1982;125: $181-4$. 
16 Killian KJ, Leblanc P, Martin DH, et al. Exercise capacity and ventilatory, circulatory, and symptom limitation in patients with chronic airflow limitation. Am Rev Respir Dis 1992;146:935-40.

17 Murciano D, Auclair MH, Pariente R, et al. A randomized, controlled trial of theophylline in patients with severe chronic obstructive pulmonary disease. N Engl $\mathcal{f} \mathrm{Med}$ 1989;320:1521-5.

8 Teramoto S, Fukuchi Y, Orimo H. Effects of inhaled anticholinergic drug on dyspnea and gas exchange during exercise in patients with chronic obstructive pulmonary disease. Chest 1993;103:1774-82. 